\title{
Acute Myeloid Leukemia in Children: Emerging Paradigms in Genetics and New Approaches to Therapy
}

\author{
Shannon E. Conneely ${ }^{1}$ (D) Alexandra M. Stevens ${ }^{1}$ \\ Accepted: 17 December 2020 / Published online: 13 January 2021 \\ (C) The Author(s) 2021
}

\begin{abstract}
Purpose of Review Acute myeloid leukemia (AML) in children remains a challenging disease to cure with suboptimal outcomes particularly when compared to the more common lymphoid leukemias. Recent advances in the genetic characterization of AML have enhanced understanding of individualized patient risk, which has also led to the development of new therapeutic strategies. Here, we review key cytogenetic and molecular features of pediatric AML and how new therapies are being used to improve outcomes.

Recent Findings Recent studies have revealed an increasing number of mutations, including WT1, CBFA2T3-GLIS2, and KAT6A fusions, DEK-NUP214 and NUP98 fusions, and specific KMT2A rearrangements, which are associated with poor outcomes. However, outcomes are starting to improve with the addition of therapies such as gemtuzumab ozogamicin and FLT3 inhibitors, initially developed in adult AML.

Summary The combination of advanced risk stratification and ongoing improvements and innovations in treatment strategy will undoubtedly lead to better outcomes for children with AML.
\end{abstract}

Keywords Risk stratification $\cdot$ Epigenetic $\cdot$ Chemotherapy $\cdot$ Immunotherapy $\cdot$ Tyrosine kinase $\cdot$ Outcomes

\section{Introduction}

Pediatric acute myeloid leukemia (AML) is a heterogeneous disease with generally poor outcomes compared to childhood lymphoid leukemia. Decades of coordinated efforts through cooperative group trials have improved our understanding of the unique biology underlying pediatric AML and patient outcomes. However, relapse remains frequent with limited available treatment options. As AML is more common and heavily researched in older adults, the field of pediatric AML has advanced in the understanding of AML biology and novel therapeutic strategies by translation of adult studies into the realm of pediatrics. However, there are substantial differences in the mutational landscape in pediatric versus adult AML and

This article is part of the Topical Collection on Pediatric Oncology

Shannon E. Conneely seconnee@texaschildrens.org

1 Department of Pediatric Hematology/Oncology, Baylor College of Medicine/Texas Children's Hospital, 6701 Fannin, Suite 1510, Houston, TX 77030, USA tolerance to treatment regimens, thus requiring dedicated risk stratification and treatment considerations in children.

Compared to adults, children with AML have superior outcomes due to fewer adverse genetic mutations and the ability to tolerate the high-intensity chemotherapy currently necessary for cure. While complete remission (CR) rates are high in pediatric AML at approximately $90 \%$, event-free survival (EFS) and overall survival (OS) remain suboptimal at $45 \%$ and $65 \%$, respectively, at 3 years, and nearly half of children will relapse [1,2]. Even in the low-risk genetic groups, relapse remains common at up to $35 \%$. Unfortunately, children at the highest risk of relapse related to poor genetic features have dismal outcomes altogether and continue to require stem cell transplant (SCT) to achieve cure, with only one in three surviving at 3 years [1].

Treatment decisions, namely the need for SCT, in pediatric AML are primarily driven by genetic risk classification which is quickly evolving. The World Health Organization (WHO) began defining recurrent genetic groups in myeloid malignancies in 2001 due to high incidence of specific mutations in AML, unique underlying biology, and comparable outcomes amongst patients with these lesions [3]. However, these definitions are primarily based on adult studies, and while an overlap between genetic features in adults and children exists, 
assigning risk categories in children requires special consideration. Currently, $\mathrm{t}(15 ; 17)$, the defining genetic rearrangement of acute promyelocytic leukemia, is excluded from most AML studies due to highly specific therapy and superior outcomes and will not be discussed here. Favorable-risk genetics such as inv(16), $\mathrm{t}(8 ; 21)$, and CEBPA and NPM1 mutations may be cured with chemotherapy alone [4-6]. In contrast, monosomy 7 and monosomy 5 or $5 q$ deletions are high-risk (HR) features which require SCT in first remission for the best outcomes [7, 8]. Rearrangements of $K M T 2 A$, located on chromosome $11 \mathrm{q} 23$, were also included in initial WHO classifications, but the prognostic significance was unclear until recently $[9$, $10 \bullet \cdot$. As advanced testing abilities and mutation profiling have become more readily available, these genetic risk groups are rapidly changing. Through collaborative efforts such as the Therapeutically Applicable Research to Generate Effective Treatments (TARGET) AML initiative, in-depth descriptions of pediatric AML mutations and their effects on outcomes have been achieved [10••].

Along with improving our understanding of the biology of AML, identification of recurrent mutations has provided an opportunity to develop new treatment approaches. Targeted therapeutics, epigenetic modifiers, immune-based strategies, and novel metabolic pathway inhibition have all been utilized recently with varying degrees of success in adult AML. These strategies are now being employed in children with the aim of improving cure rates and providing more options in the relapse setting. Here, we discuss the current progress in understanding the unique mutational landscape of pediatric AML, implications on prognosis, and the use of new treatment strategies to optimize therapy and outcomes in children with AML.

\section{Genetics}

\section{Established Genetic Risk Factors}

Risk stratification in pediatric AML has previously been based on the presence of a handful of genetic features and responses to therapy. Those with favorable genetics include $\mathrm{t}(8 ; 21)$, inv(16), NPM1 mutations, and CEBPA mutations, each of which carries EFS and OS rates of approximately $65-70 \%$ and $80 \%$, respectively $[1,4,11] . \mathrm{t}(8 ; 21)$ and inv(16), collectively termed core binding factor (CBF) AML, represent the most common cytogenetic subgroup in pediatric AML accounting for $20-25 \%$ of cases $[1,10 \bullet, 11]$. Mutations in NPM1 and CEBPA are more recent additions to the favorable prognostic group and are similarly associated with an improved prognosis in both children and adults [5]. CEBPA encodes a transcription factor that regulates expression of myeloid-specific genes with recurrent mutations occurring in two functional domains in approximately $4 \%$ of pediatric AML [4]. NPM1 is a primarily nucleolar protein which plays a role in regulating p53 function and other cellular processes and, when mutated in AML, aberrantly localizes to the cytoplasm [5]. NPM1 mutations are more common with increasing age but do occur in about $5-10 \%$ of children compared to $30 \%$ of adults $[5,10 \bullet \cdot 12,13 \bullet]$. Pediatric studies demonstrate a higher EFS and OS with NPMI mutations, particularly in cytogenetically normal AML or when they occur in the context of HR mutations where the presence of mutated NPMI may improve outcomes compared to the HR genetic feature alone $[5,6,10 \bullet \cdot$.

In contrast to the favorable outcomes associated with $\mathrm{CBF}$ AML and NPM1 or CEBPA mutations, certain HR features have consistently shown poor outcomes in children and adults over the decades. This includes monosomy of chromosome 7 or 5 or deletion of $5 \mathrm{q}$. These HR features are more common in adults and collectively occur in less than $5 \%$ of pediatric AML patients [14]. Of these, monosomy 7 is more common and carries a high rate of induction failure, EFS of $17-29 \%$, and OS of $32 \%$, a significantly worse prognosis than the HR group as a whole (EFS of 28\%; OS of 48\%) [1, 14-17]. The list of mutations conferring an HR status and overall poor outcome continues to expand as research reveals new mutations and prognostic relevance. Identification of such cytogenetic and molecular changes is the first step to targeting dependencies for these HR subtypes and ultimately improving outcomes.

\section{Tyrosine Kinase Mutations}

\section{FLT3}

FMS-like tyrosine kinase 3 (FLT3) is a recurrently mutated gene in AML, occurring in $20-25 \%$ of children and $30 \%$ of adults $[10 \bullet \bullet, 13 \bullet, 18]$. FLT3 mutations lead to constitutive activation of the tyrosine kinase domain (TKD) causing uninhibited growth and are characterized as either TKD or internal tandem duplication (ITD) mutations with FLT3-ITD being significantly more common in children (Table 1) [13•]. The prognostic relevance of the FLT3-ITD allelic ratio (AR) has been refined over the last decade. Previous trials demonstrated that an $\mathrm{AR}>0.4$ conferred a poorer prognosis compared to an $\mathrm{AR}<0.4$, and so FLT3-targeted therapy was included only for the high AR group [19]. However, updated analysis has suggested that an AR $>0.1$ is sufficient to confer unfavorable EFS of $25-30 \%$ and OS of $60 \%$ [20 ]. Therefore, children with an FLT3-ITD AR > 0.1 may benefit from FLT3 inhibitor therapy and SCT in first remission with this lower threshold being used in upcoming trials.

\section{RAS}

Mutations in the Ras pathway are the most common mutations occurring up to $40 \%$ of pediatric AML patients, primarily in either NRAS or KRAS genes [13•]. Similar to FLT3, RAS 
Table 1 Recurrent mutations in pediatric AML. Duration of survival endpoint varies depending on study

\begin{tabular}{|c|c|c|c|c|c|c|}
\hline Category & Mutation & Reference & Prevalence & Estimated EFS & Estimated OS & Special considerations \\
\hline \multirow[t]{4}{*}{ Tyrosine kinase } & FLT3/ITD AR > 0.1 & 13,20 & $15 \%$ & $25-35 \%$ & $60 \%$ & $\begin{array}{l}\text { Co-occur with } W T 1, D E K-N U P 214 \text {, } \\
\text { and NUP98 fusions }\end{array}$ \\
\hline & FLT3-TKD & 13 & $8-10 \%$ & & & \\
\hline & RAS & 13,21 & $35-40 \%$ & $65 \%$ & $81 \%$ & NRAS mutations more common than KRAS \\
\hline & KIT & 13,21 & $12 \%$ & $60 \%$ & $90 \%$ & Enriched in inv(16) and $t(8 ; 21)$ AML \\
\hline \multirow[t]{8}{*}{ Epigenetic modifiers } & $\begin{array}{l}\text { KMT2A fusions } \\
\mathrm{t}(9 ; 11)\end{array}$ & 9,27 & $\begin{array}{l}15-20 \% \\
39-43 \%{ }^{\mathrm{a}}\end{array}$ & $\begin{array}{l}44 \% \\
50 \%\end{array}$ & $\begin{array}{l}56 \% \\
63 \%\end{array}$ & Prognosis dependent on fusion partner \\
\hline & $\mathrm{t}(4 ; 11)$ & & $1-2 \%^{\mathrm{a}}$ & $29 \%$ & $27 \%$ & \\
\hline & $\mathrm{t}(6 ; 11)$ & & $5-8 \%{ }^{\mathrm{a}}$ & $11 \%$ & $22 \%$ & \\
\hline & $\mathrm{t}(10 ; 11)(\mathrm{p} 11.2 \mathrm{q} 23)$ & & $1-2 \%^{\mathrm{a}}$ & $17 \%$ & $27 \%$ & \\
\hline & $\begin{array}{l}t(10 ; 11)(p 12 q 23) \\
t(11 ; 19)\end{array}$ & & $\begin{array}{l}13 \%^{\mathrm{a}} \\
12-14 \%^{\mathrm{a}}\end{array}$ & $\begin{array}{l}31 \% \\
46-49 \%\end{array}$ & $\begin{array}{l}45 \% \\
47-61 \%\end{array}$ & $M L L-M L L T 10$ fusion \\
\hline & $\begin{array}{l}\text { MLLT10 fusion } \\
\text { (non-KMT2A) }\end{array}$ & 29,30 & $<1 \%$ & & $36 \%$ & EMD common \\
\hline & DEK-NUP214 & $13,17,32$ & $1-2 \%$ & $\begin{array}{l}32 \% \\
68 \%{ }^{\mathrm{b}}\end{array}$ & $53 \%$ & $\begin{array}{l}\text { High rates of induction failure } \\
\text { More common in }>10 \text { years of age }\end{array}$ \\
\hline & KAT6A fusion & 35 & $<0.5 \%$ & $57 \%$ & $59 \%$ & $\begin{array}{l}\text { Common in c-AML and may have } \\
\text { spontaneous remission } \\
66 \% \text { with EMD }\end{array}$ \\
\hline \multirow[t]{4}{*}{ Transcription factors } & WT1 mutation & 10,13 & $10-15 \%$ & $30 \%$ & $45 \%$ & $\begin{array}{l}\text { Often co-occurs with NUP98 } \\
\text { fusion or FLT3/ITD }\end{array}$ \\
\hline & ETV6 fusions & $10,30,37,44$ & $<1 \%$ & $43 \% \mathrm{~b}$ & $\begin{array}{l}12 \% \\
100 \%\end{array}$ & $\begin{array}{l}\text { Most common in }<18 \text { months of age } \\
\text { MNX1-ETV6 found in } 30 \% \text { infant AML }\end{array}$ \\
\hline & CBFA2T3-GLIS2 & 17,41 & $2 \%$ & $16.7 \%$ & $41.7 \%$ & $27 \%$ of M7 AML \\
\hline & NUP98 fusion & $13,17,21,41$ & $5-10 \%$ & $13-17 \%$ & $33.3-52 \%$ & $9 \%$ of $\mathrm{M} 7 \mathrm{AML}$ \\
\hline \multirow[t]{3}{*}{ Others } & FUS-ERG & 17,30 & $<1 \%$ & $9 \%$ & $31 \%$ & \\
\hline & MECOM fusion & 30 & $<1 \%$ & $9 \%$ & $31 \%$ & \\
\hline & NPM1-MLF1 & 30 & $<1 \%$ & & & \\
\hline
\end{tabular}

EFS event-free survival, $O S$ overall survival, $A R$ allelic ratio, EMD extra-medullary disease, $c-A M L$ congenital AML, SCT stem cell transplant

${ }^{\text {a }}$ Percentage of KMT2A rearrangements

${ }^{\mathrm{b}}$ With SCT

mutations lead to constitutive activation of the Ras pathway. Despite intense research in associating $R A S$ mutations with outcome, they do not independently alter relapse risk or survival measures in pediatric AML in general, but they may play a prognostic role in specific subtypes [21]. For example, in CBF AML, RAS-mutated patients have a lower risk of relapse, though this is not integrated into current risk stratification algorithms [22]. Importantly, $R A S$ mutations may play a role as a therapeutic target as many new therapies utilize tyrosine kinase (TK) inhibition to limit cell growth. Mutations in Ras pathway genes are also found to associate with rearrangements in KMT2A, though this relationship appears to be most common in infant acute lymphoblastic leukemia [23].

\section{KIT}

Mutations in the tyrosine kinase receptor KIT gene occur in $12 \%$ of pediatric AML patients and typically lead to unregulated function of the KIT protein $[10 \bullet, 13 \bullet$, 24]. These mutations occur in two hotspot locations in the gene, exon 8 and exon 17, though only exon 17 mutations have definitively been shown to cause KIT auto-phosphorylation and constitutive activation [25]. Though previous studies have not determined a prognostic value of KIT mutations in pediatric AML as a whole, others have shown an improved OS associated with KIT mutations $[13 \bullet, 21]$. These recent results may be due to an enrichment of KIT mutations in the favorable-risk CBF AML group, as KIT mutations occur in $24-36 \%$ of this population with a slight predominance for exon 17 mutations [22, 26]. While studies in $\mathrm{CBF}$ AML as a whole also do not demonstrate a prognostic significance of KIT mutations, such mutations within the $\mathrm{t}(8 ; 21)$ subgroup of AML increase the risk of relapse and lead to an inferior OS of only $50 \%$ at 4 years $[22,26]$. 


\section{Epigenetic Modifiers}

\section{KMT2A Rearrangements}

Lysine methyltransferase 2a encoded by KMT2A (formerly $M L L)$ regulates gene expression via methylation of histone residues and epigenetic modifications. It is located on chromosome $11 \mathrm{q} 23$ and is frequently involved in gene rearrangements in AML with a multitude of fusion partners. KMT2A rearrangements were included in the original WHO AML classification, but the prognostic significance in adults was unclear. KMT2A rearrangements are more common in children than adults with a particularly high occurrence in infant AML, and the fusion partner profile is also unique to each age group $[16,27 \cdot \bullet]$. While studies in children show that KMT2A rearrangements are clearly associated with inferior outcomes with an EFS of $44 \%$ and an OS of $56 \%$ along with higher rates of early death and relapse, the true prognostic value is highly dependent on the fusion partner gene (Table 1) $[9,15,28]$. The KMT2A-MLLT3 fusion resulting from $\mathrm{t}(9 ; 11)(\mathrm{p} 22 ; \mathrm{q} 23)$ is the most common KMT2A rearrangement in children, yet over 100 different fusion partners have been identified $[15,16]$. Of the recurrent fusions, $\mathrm{t}(6 ; 11)(\mathrm{q} 27 ; \mathrm{q} 23)$ and $\mathrm{t}(10 ; 11)(\mathrm{p} 12 ; \mathrm{q} 23)$ have the worst outcomes with a 5 -year OS of approximately $30 \%[9,28]$. Interestingly, MLLT10, the fusion partner in $\mathrm{t}(10 ; 11)(\mathrm{p} 12 ; \mathrm{q} 23)$, also pairs with other genes in novel fusion events $[10 \bullet \bullet, 29,30 \bullet$. Other KMT2A rearrangements such as $\mathrm{t}(4 ; 11)(\mathrm{q} 21 ; \mathrm{q} 23)$ and $\mathrm{t}(11 ; 19)(\mathrm{q} 23 ; \mathrm{p} 13.3)$ are now considered HR fusions due to their associated high relapse risk $[9,28]$. In contrast, one study demonstrated a $100 \% 5$-year OS and a $92 \%$ EFS in 25 children harboring $\mathrm{t}(1 ; 11)(\mathrm{q} 21 ; \mathrm{q} 23)$ [9]. Due to the low frequency of novel KMT2A fusions, not all rearrangements have welldefined outcomes, but careful consideration should be given to the fusion partner when considering the treatment approach for such patients.

\section{DEK-NUP214 Fusion}

AML with $\mathrm{t}(6 ; 9)(\mathrm{p} 22 ; \mathrm{q} 34)$, a translocation leading to $D E K$ NUP214 fusion, represents less than $2 \%$ of children with AML [31-33]. DEK is involved in chromatin structure and transcriptional regulation, whereas NUP214 regulates transport of structures between the nucleus and cytoplasm [33]. In children, international studies demonstrate a high rate of induction failure with only $67 \% \mathrm{CR}$ along with 5 -year OS of $39-53 \%$, EFS of $32 \%$, and relapse rate of $57-64 \%$ [31, 32]. This fusion is more common in older children with a median age of 10.4 years. While some studies suggest that the presence FLT3-ITD does not independently alter outcomes in this subgroup, a recent Children's Oncology Report (COG) report showed a superior EFS in those with $\mathrm{t}(6 ; 9)$ that also harbored FLT3-ITD, likely due to the fact that all FLT3-ITD-positive patients received SCT in 1 st $\mathrm{CR}[31,32]$. In both the
American and European experiences, SCT in 1st CR for patients with $\mathrm{t}(6 ; 9)$ significantly improved EFS to $68 \%$ compared to $0-18 \%$ in those who received chemotherapy alone, demonstrating a clear role for SCT in the treatment of $D E K$ NUP214 AML [31, 32].

\section{KAT6A Fusion}

Translocations involving $8 \mathrm{p} 11$ are a newly described entity in AML, which lead to fusion of KAT6A, a histone acetyltransferase, with a partner gene, most commonly CREBBP on $16 \mathrm{p} 13$. In adults, this fusion is often found in younger patients with unique clinical characteristics such as leukemia cutis, disseminated intravascular coagulation, and hemophagocytosis [34]. In children, this rare fusion is strongly associated with congenital AML, presenting this way in over $25 \%$ of described cases [35]. Amongst all presentations of KAT6A fusions, current reports demonstrate a 5-year EFS and an OS of 55-60\% in those who undergo therapy with curative intent and often undergo SCT in first remission [35]. Relapses tend to occur within the first year of diagnosis. Of particular interest is the natural progression in congenital AML with KAT6A fusions, where spontaneous remission often occurs, though $50 \%$ will subsequently have return of their disease [35].

\section{Transcription Factors and Other Fusions}

\section{WT1}

Wilms' tumor 1 (WT1) gene is commonly mutated across different malignancies and regulates quiescence in hematopoietic progenitors as well as differentiation of myeloid cells [21]. Mutations in WT1 occur in approximately 10 $15 \%$ of childhood AML and are more likely to be clonal than in adults $[10 \bullet \bullet, 13 \bullet, 36]$. In half of children with WT1 mutations, both alleles are affected either by mutation or by deletion [36]. In addition, WT1 mutations frequently cooccur with aberrations such as FLT3-ITD and NUP98 fusions $[21,36]$. WT1 mutations are independent poor prognostic factors with a 5 -year OS of $35 \%$ and EFS of $22 \%$ in children [36]. In addition, CR rates are significantly lower in children with WT1 mutations [13•]. The combination of WT1 mutation and FLT3-ITD confers an even poorer prognosis with an OS of $21 \%$ and EFS of $15-30 \%$ and a significantly higher rate of relapse, though these outcomes do not reflect the most recent clinical trials $[10 \bullet \bullet, 21]$.

\section{ETV6 Abnormalities}

Fusions with ETV6, common in lymphoid leukemias, have also been identified in pediatric myeloid malignancies at a lower frequency. The fusion of ETV6 with $M N X 1$, resulting from $\mathrm{t}(7 ; 12)(\mathrm{q} 36 ; \mathrm{p} 13)$, was originally 
described in infant AML and associated with an extremely poor prognosis with a 3-year EFS and OS of $0 \%[37,38]$. Recently, MNX1-ETV6 has been identified outside of infancy where it frequently co-occurs with trisomy 19 and has better outcomes than previously reported [38]. While high rates of relapse have been consistently demonstrated, the 3 -year OS in a recent European study was $100 \%$ as patients had improved outcomes with SCT following relapse [37]. ETV6 has also been found to fuse with numerous other genes in pediatric AML and to be associated with inferior survival, leading to the recent inclusion of ETV6 fusions in the HR genetic stratification [10••, 30•]. In addition to fusions, loss of ETV6 via chromosome $12 \mathrm{p}$ deletion is also associated with a poor prognosis [16].

\section{CBFA2T3-GLIS2}

CBFA2T3-GLIS2 fusion results from a cryptic translocation in chromosome 16 [39]. It was first described in children with non-Down syndrome acute megakaryoblastic leukemia (AMKL) where it occurs in $30 \%$ of children, but has recently been described in approximately $8 \%$ of AML patients less than 3 years of age [39-41]. CBFA2T3-GLIS2 has a predisposition for African American children which make up nearly $1 / 3$ of patients with the fusion [40]. These children have previously been treated with standard therapy as the CBFA2T3GLIS2 fusion does not co-occur with traditional HR karyotypes [40]. On retrospective analysis of clinical trials, children with CBFA2T3-GLIS2 had far inferior outcomes with only $50 \%$ achieving $\mathrm{CR}$ at the end of first induction and $35 \%$ having persistent MRD after induction 2. Both EFS and OS are poor at only $20-40 \%$ at 5 years regardless of having the AMKL phenotype $[17,39]$. These children reflect a previously undefined group of HR children who may benefit from early SCT.

\section{NUP98 Fusions}

NUP98, a nucleoporin gene, has been of recent interest due to its fusion with NSD1 in $\mathrm{t}(5 ; 11)(\mathrm{q} 35 ; \mathrm{p} 15)$ in less than $5 \%$ of pediatric AML patients $[13 \cdot, 21]$. NUP98NSD1 is not found in combination with other cytogenetic rearrangements, but it frequently co-occurs with FLT3ITD or WT1 mutations, with one or both genes mutated in $80 \%$ of patients $[13 \cdot, 21,24,42]$. NUP98 fusions in children independently increase the risk of relapse and decrease CR, EFS, and OS [13•, 21, 42]. NUP98 fusions combined with either FLT3-ITD or WT1 mutations have an even worse prognosis than NUP98 fusions alone, with a relapse rate over $75 \%$ and an OS of $20-40 \%[21,42]$. Clinically, these fusions are associated with a higher presenting white blood cell (WBC) count and older patient age [43]. A second recurrent fusion with NUP98 is the
NUP98-KDM5A fusion, identified in $2 \%$ of children from recent American and European trials [43]. In contrast to NUP98-NSD1, the NUP98-KDM5A fusion is more common in young children and most common in AMKL where it was originally described $[17,43]$. The NUP98KDM5A fusion rarely co-occurs with WT1 or TK mutations, yet still has a very poor prognosis. The 5-year EFS and OS of this group are 16-39\% and 33-34\%, respectively $[17,43]$. Importantly, of those who underwent SCT in 1 st remission, $71 \%$ still subsequently relapsed, demonstrating an ongoing need for better therapies [17].

\section{Other Mutations}

Additional rare gene fusions and mutations exist which are associated with inferior survival. However, the small number of children in which these mutations occur has limited the ability to study such genetics in detail, including accurate survival statistics [30•, 44]. These include RPN1- and RUNX1-MECOM fusions, NPM1-MLF1, and $F U S-E R G$ [17, 30•]. Many of these fusions occur due to cryptic rearrangements and were previously unidentified when use of fluorescent in situ hybridization was the predominant means of diagnosing genetic abnormalities. The use of advanced genetic testing strategies, such as RTPCR, has since improved the detection of these negative prognostic markers and is an essential tool to correctly assess patient risk [10••, 30•, 44]. Recognition of each of these HR genetic features in pediatric AML is necessary to improve outcomes.

\section{New Therapy}

\section{Current Treatment Approach}

While outcomes in pediatric AML have improved over the decades, these advances have been primarily due to early intensification of therapy, early use of SCT in HR patients, and improvements in supportive care. Current regimens still rely heavily on high-dose chemotherapy including cytarabine and anthracyclines in order to induce remissions. These agents carry a serious risk of toxicity including infection and cardiac dysfunction. Despite high doses of cytotoxic chemotherapy, relapse remains a frequent problem in pediatric AML. The newer treatment approaches discussed below have only recently been introduced in pediatric clinical trials (Table 2). These agents were typically developed and studied in older adults unable to tolerate the intensity of standard therapies, including SCT, and are now being translated into pediatric AML care. 
Table 2 New therapeutics in pediatric AML

\begin{tabular}{|c|c|c|}
\hline Drug & Mechanism of action & Current stage of development in pediatric AML \\
\hline \multicolumn{3}{|l|}{ Drug-antibody conjugates } \\
\hline Gemtuzumab ozogamicin [14] & Anti-CD33 antibody with calicheamicin payload & $\begin{array}{l}\text { FDA-approved for newly diagnosed } \\
\text { AML }>1 \text { month of age } \\
\text { Standard of care as single dose in induction } 1\end{array}$ \\
\hline Flotetuzumab [58] & CD123/CD3 bispecific dual-affinity retargeting antibody & Phase I trials for $\mathrm{r} / \mathrm{r}$ AML \\
\hline Nivolumab [61] & Anti-PD-1 antibody/checkpoint inhibitor & Phase I/II trial for $\mathrm{r} / \mathrm{r}$ AML combined with azacitidine \\
\hline \multicolumn{3}{|l|}{ Epigenetic modifiers } \\
\hline Decitabine [67] & Hypomethylating agent: inhibits DNA methyltransferases & $\begin{array}{l}\text { Completed phase I trial for } r / r \text { AML } \\
\text { Phase II trial with standard chemotherapy } \\
\text { in newly diagnosed AML }\end{array}$ \\
\hline Azacitidine [68] & Hypomethylating agent: inhibits DNA methyltransferases & $\begin{array}{l}\text { Phase I/II trials for } \mathrm{r} / \mathrm{r} \text { AML } \\
\text { Phase II trial with standard chemotherapy in } \\
\text { newly diagnosed AML }\end{array}$ \\
\hline Vorinostat [72] & Inhibits histone deacetylase & Phase I trial for $\mathrm{r} / \mathrm{r}$ AML \\
\hline Panobinostat [71] & Inhibits histone deacetylase & Phase I trial for $\mathrm{r} / \mathrm{r}$ AML \\
\hline \multicolumn{3}{|l|}{ Tyrosine kinase/FLT3 inhibitors } \\
\hline Sorafenib $[80]$ & $\begin{array}{l}\text { 1st-generation type II TKI: active against } \\
\text { FLT3-ITD and FLT3-TKD mutations }\end{array}$ & $\begin{array}{l}\text { Completed phase III trials for high } \\
\text { AR FLT3-ITD AML }\end{array}$ \\
\hline Midostaurin [83] & $\begin{array}{l}\text { 1st-generation type I TKI: active against FLT3 } \\
\text { and KIT mutations }\end{array}$ & $\begin{array}{l}\text { USA: phase I/II trials terminated for low enrollment } \\
\text { International: ongoing phase II trial }\end{array}$ \\
\hline Gilteritinib [87] & 2nd-generation type I TKI: active against $F L T 3$ and $A X L$ & $\begin{array}{l}\text { Phase III trials combined with standard } \\
\text { chemo in newly diagnosed AML } \\
\text { Phase I/II trial combined with FLAG for } r / r \text { AML }\end{array}$ \\
\hline Quizartinib [75] & Type II TKI & Phase $\mathrm{I} / \mathrm{II}$ trials in $\mathrm{r} / \mathrm{r}$ AML \\
\hline Crenolanib [75] & Type I TKI & Completed phase I trial in $\mathrm{r} / \mathrm{r}$ leukemias \\
\hline \multicolumn{3}{|l|}{ Others } \\
\hline Venetoclax [99] & Inhibits BCL-2 & Phase I/II trials for $\mathrm{r} / \mathrm{r}$ AML \\
\hline CPX-351 [99] & $\begin{array}{l}\text { Liposomal formulation of daunorubicin and } \\
\text { cytarabine-enhances synergy between drugs } \\
\text { and extends half-life }\end{array}$ & $\begin{array}{l}\text { Completed phase I/II trials for } \mathrm{r} / \mathrm{r} \text { AML } \\
\text { Current phase III trial for newly diagnosed AML }\end{array}$ \\
\hline Atovaquone [99] & Inhibits oxidative phosphorylation and STAT3 activation & Phase I trial with standard chemotherapy \\
\hline \multicolumn{3}{|l|}{ Chimeric antigen receptor $\mathrm{T}$ cells } \\
\hline CD123-targeting CAR-T [62] & $\begin{array}{l}\text { T cells genetically modified to target/kill } \\
\text { CD123-expressing AML cells }\end{array}$ & Phase I trials for $\mathrm{r} / \mathrm{r}$ AML \\
\hline CD33-targeting CAR-T [46] & $\begin{array}{l}\text { T cells genetically modified to target/kill } \\
\text { CD33-expressing AML cells }\end{array}$ & Phase I trials for $\mathrm{r} / \mathrm{r} \mathrm{AML}$ \\
\hline
\end{tabular}

FDA, Food and Drug Administration; $r / r$, relapsed/refractory; TKI, tyrosine kinase inhibitor; ITD, internal tandem duplication; TKD, tyrosine kinase domain; $A R$, allelic ratio; $F L A G$, fludarabine, cytarabine, granulocyte colony-stimulating factor; $C A R-T$, chimeric antigen receptor T cell

\section{Immune-Based Therapy}

\section{Drug-Antibody Conjugates}

Targeted therapy which exploits cell surface markers unique to cancer cells has been a significant therapeutic advance in cancer treatment. In drug-antibody conjugates, antibody targeting can deliver a drug, such as the small molecule calicheamicin, directly to cells of interest. Gemtuzumab ozogamicin (GO) is one such treatment where calicheamicin is conjugated to an anti-CD33 antibody and has potent antitumor effects on CD33-expressing cells, found in a majority of AML cases $[45,46]$. Despite initial adult studies demonstrating improvements in EFS and OS when used in upfront or relapse therapy, GO was pulled from the market due to its increased toxicities [47, 48]. More recent studies have demonstrated that lower doses of GO can produce similar outcomes with less treatment-related mortality, leading to reapproval of GO in adult AML therapy [49, 50]. GO was subsequently incorporated into pediatric clinical trials in both relapsed and upfront therapies where it improved EFS and reduced relapse risk; however, OS and CR rates remained unchanged $[14,51]$. The reduced relapse risk $(32.8 \%$ vs. $41.3 \%)$ when GO was given in upfront therapy in COG AAML0531 
was offset by increased treatment-related mortality $(8.6 \%$ vs. $5.9 \%$ ) [14]. Newer studies are therefore designed to maximize benefit while limiting toxicity by giving $\mathrm{GO}$ as a single dose in induction, as this has been shown to have the highest benefit and may reduce toxicity profiles $[14,52]$. Children more likely to benefit from GO therapy include those with FLT3-ITD mutations, $K M T 2 A$ rearrangements, single-nucleotide polymorphisms in $A B C B 1$ and $C D 33$, and high CD33 expression, but these are not currently factored into treatment decisions [18, 53-55].

CD123, the IL-3 receptor $\alpha$-chain, has also been a cell surface target of interest in AML owing to its expression in a majority of AML cases, including leukemic stem cells [56]. CD123-targeted therapies remain in the early phases of development but may provide an additional avenue of treatment. To date, several antibody conjugates have been explored, including a CD123-targeting drug conjugate in which an antiCD123 antibody is linked to the alkylating agent indolinobenzodiazepine pseudodimer and a dual-affinity retargeting (DART) CD3-CD123 platform which assists $\mathrm{CD}^{+} \mathrm{T}$ cells in recognizing and eliminating CD123expressing cells $[57,58]$. The CD3-CD123 DART is currently in pediatric early-phase clinical trials.

Interest has also recently grown in the use of checkpoint inhibitors in AML to enhance the immune response to cancerous cells. This strategy has been used successfully in adult solid tumors but remains experimental in AML. Currently available checkpoint inhibitors include nivolumab and pembrolizumab, anti-PD-1 antibodies, and ipilimumab, which targets CTLA-4. Early clinical trials in adult AML have shown that checkpoint inhibition, either as monotherapy or in combination with other treatments, is a feasible and safe strategy now being explored in larger studies [59]. Nivolumab has also been successfully used in adults who relapse following SCT to regain donor chimerism without the need for second transplant [60]. The only reported use in pediatric AML was in a child with highly refractory relapsed AML in combination with azacitidine in which the child had symptomatic relief after therapy but failed to have any significant improvement in disease burden, though phase I/II clinical trials in children with AML have recently begun (NCT03825367) [61].

\section{Chimeric Antigen Receptor T Cells}

Immunotherapy with chimeric antigen receptor T cells (CART) for AML has lagged significantly behind lymphoid leukemias in development and effectiveness. The heterogeneity of AML has made it challenging to identify adequate leukemiaspecific antigens which do not also produce on-target off-tumor effects on normal tissue. CD33 and CD123 are expressed in $90 \%$ and $75 \%$ of AML, respectively, with less than $5 \%$ of cases being negative for both [56]. While CD33-directed therapies also target non-leukemic mature and progenitor myeloid cells, the lack of CD33 expression in hematopoietic stem cells coupled with the success of GO has provided rationale for investigation into the use of CD33-directed CAR-Ts [46]. CD123 is expressed at high levels in multiple types of hematologic malignancies, making it an attractive target across leukemia types [62]. However, CD123 is also expressed on normal hematopoietic stem cells and may therefore be most useful as a bridge to SCT. Both CD33- and CD123-directed CAR-T trials are currently underway in pediatric studies for relapsed/ refractory AML (NCT04318678, NCT03971799). Due to concerns for on-target off-tumor effects, it is likely that sophisticated targeting strategies such as dual-targeting or switchable CAR-Ts will be required to avoid serious toxicity [56, 62].

\section{Epigenetic Modifiers}

\section{Hypomethylating Agents}

The prevalence of epigenetic dysregulation in AML development has led to a rising interest in targeting epigenetic modifiers as part of therapy. Hypomethylating agents (HMAs) such as decitabine and azacitidine are DNA methyltransferase (DNMT) inhibitors which alter DNA methylation patterns, leading to increased expression of tumor suppressors and apoptosis [63]. In adults, these therapies prolong survival but rarely lead to sustained remission when used as a single agent [64]. Decitabine has also been used as maintenance therapy for adults with AML but did not protect against relapse when used in this setting [65]. In children, case reports and small earlyphase trials incorporating DNMT inhibitors have demonstrated reasonable safety profiles and efficacy in the relapse setting, but large studies have not been completed [66, 67]. One study utilized azacitidine in combination with fludarabine and cytarabine chemotherapy and achieved CR in 7/12 children with relapsed or refractory AML [68]. The use of HMAs in upfront treatment with cytotoxic chemotherapy is currently being investigated in the St. Jude AML16 trial (NCT03164057).

\section{HDAC Inhibitors}

Histone deacetylases (HDACs) contribute to epigenetic regulation via the removal of acetyl groups from histones condensing chromatin and decreasing gene transcription. Inhibition of HDAC activity remodels chromatin in AML cells with attendant decreased expression of DNA repair genes, depletion of CXCR4, cell cycle arrest, and ultimately apoptosis, with these effects being synergistic with standard chemotherapy regimens $[69,70]$. The two HDAC inhibitors which have been investigated in AML include vorinostat and panobinostat which are FDA-approved for refractory multiple myeloma and cutaneous $\mathrm{T}$ cell lymphoma, respectively. Preclinical studies demonstrate that the effects of HDAC inhibitors are maximized when given with other drugs such as HMAs where 
they serve as epigenetic sensitizers [71, 72]. While adult studies have had mixed results, HDAC inhibitors can be safely combined with other agents such as DNMT inhibitors and relapse regimens and are currently being investigated in relapsed pediatric AML (NCT03263936) [73, 74].

\section{FLT3 Inhibitors}

FLT3-mutated AML has been a specific disease subset of interest due to the targetable nature of tyrosine kinases. FLT3 inhibitors are small molecules which bind to the adenosine triphosphate-binding site on FLT3 leading to competitive inhibition of kinase activity [75]. The drugs are categorized as type I or type II inhibitors with both affecting ITD mutations, but type I inhibitors are also active against TKD mutations and have higher binding affinity for FLT3 [76]. In addition, first-generation inhibitors have multikinase activity with lower specificity for FLT3 and more off-target effects, whereas second-generation inhibitors are more specific for FLT3 activity. There are at least 8 FLT3 inhibitors currently on the market or under development, though none is approved for use in children. Sorafenib is a multikinase type II inhibitor and one of the first used in the treatment of AML. When combined with chemotherapy, sorafenib improved CR and EFS regardless of FLT3 mutation status in younger adults with AML, but also increased toxicity [77, 78]. Early-phase clinical trials in children with relapsed AML demonstrated that sorafenib was tolerable and effective when given with chemotherapy [79]. Sorafenib was therefore added to treatment of children with newly diagnosed, high AR FLT3-ITD AML, including 1 year of maintenance therapy in the most recent COG trial. Preliminary results demonstrate that addition of sorafenib increases CR and EFS and decreases relapse risk in children with high AR FLT3-ITD, providing rationale for ongoing use of FLT3 inhibitors in children [80].

Midostaurin, the first FDA-approved FLT3 inhibitor, is a first-generation type I FLT3 inhibitor with off-target effects on KIT and was shown to decrease blast percentages in patients with relapsed/refractory AML when used as a single agent regardless of FLT3 mutation status [81]. The large multinational RATIFY study demonstrated that standard chemotherapy (plus SCT) plus midostaurin prolonged survival and decreased relapse risk compared to chemotherapy and SCT alone [82]. Preclinical studies of midostaurin in patientderived xenograft models were promising, but clinical trial use has been limited by low enrollment and the introduction of second-generation inhibitors [83].

Gilteritinib is a second-generation type I FLT3 inhibitor which also inhibits AXL, a tyrosine kinase which enhances FLT3 activation and serves as a mechanism for FLT3 inhibitor resistance [84]. It was FDA-approved in adults with relapsed/ refractory FLT3-mutated AML after demonstrating a tolerable safety profile with a $20-30 \%$ CR rate and significantly prolonged survival when given as monotherapy $[85,86]$. Preclinical models showed that the combination of gilteritinib with either azacitidine or cytarabine and anthracyclines further potentiated anti-leukemic effects [87]. While pediatric studies are currently lacking, two upcoming pediatric trials will investigate the use of gilteritinib in FLT3-mutated AML in combination with chemotherapy in both the relapse and upfront settings (NCT04240002, NCT04293562). Newer FLT3 inhibitors such as quizartinib and crenolanib are currently being investigated as well and appear to have similar efficacy to the approved FLT3 inhibitors [88].

\section{Other Therapeutics}

\section{BCL-2 Inhibition}

Venetoclax inhibits BCL-2, an anti-apoptotic protein whose overexpression is a mechanism of resistance in AML [89]. In adults, venetoclax with HMAs or low-dose cytarabine is both tolerable and improves response rates when used as part of low-intensity front-line therapies, but its utility in relapse remains unclear [90]. Pediatric studies are still in early phases, but initial studies demonstrated a CR of $70 \%$ when used in combination with cytarabine with or without idarubicin [91]. Preclinical studies also suggest that venetoclax works synergistically with FLT3 inhibitors midostaurin and gilteritinib to induce apoptosis in AML cells, and may provide another therapeutic avenue [92].

\section{Liposomal Chemotherapy}

A liposomal formulation of traditional chemotherapy agents cytarabine and daunorubicin, termed CPX-351, optimizes pharmacodynamics and synergistic effects via maintenance of the optimal 5:1 molar ratio which extends the half-life and enhances uptake in the bone marrow [93, 94]. The use of CPX-351 in adults demonstrated superior remission rates compared to conventional chemotherapy, though improvements in EFS and OS were limited to those with secondary AML $[95,96]$. In children, a phase I/II study in relapsed/ refractory AML demonstrated a high response rate with $75 \%$ achieving a CR after a single course of CPX-351, 80\% of whom were negative for MRD [97•]. A total of $96.7 \%$ of patients with a $\mathrm{CR}$ subsequently received additional relapse therapy with fludarabine, cytarabine, and granulocyte-colonystimulating factor followed by SCT. The OS for the entire patient population was $52.7 \%$ at 2 years from study entry. While CPX-351 has demonstrated promising early results and is being incorporated into upfront therapy for HR children in upcoming trials, it maintains a similar side effect profile to the conventional formulations of daunorubicin and cytarabine $[95,96,97 \bullet]$. 


\section{Oxidative Phosphorylation Inhibitors}

Other therapeutic strategies rely on rebranding older medications for new purposes, such as atovaquone, an antibacterial and antimalarial medication which inhibits electron transport and is approved for use in the prevention of Pneumocystis jirovecii pneumonia (PJP) [98]. Recent studies have shown that atovaquone has effects on AML cells by inhibiting STAT3 phosphorylation and subsequent expression of STAT3 target genes [99]. In preclinical studies, atovaquone induces apoptosis in AML cells, inhibits the mechanistic target of rapamycin, and inhibits oxidative phosphorylation (oxphos), leading to prolonged survival in patient-derived xenograft models [100]. In adults, atovaquone is commonly used in post-SCT for PJP prophylaxis, and one retrospective study demonstrated that adults with AML who underwent SCT with prolonged atovaquone use had lower relapse rates than those with shorter atovaquone exposure, providing further rationale for clinical use of atovaquone for AML [99]. In children, an ongoing multi-institution feasibility study uses atovaquone for PJP prophylaxis in AML patients receiving traditional chemotherapy (NCT03568994). Metformin and lonidamine have also been identified as oxphos inhibitors with anti-tumor effects in vitro, though lonidamine is not commercially approved in the USA [101].

\section{Conclusion}

The outcomes in pediatric AML, while improved in recent decades, remain suboptimal with high rates of relapse and few options for therapy when initial treatment regimens fail. Genetic risk grouping has gone a long way to target the intensity of therapy to those at the highest risk of relapse and death; however, the heterogeneous nature of AML has left many HR genetic features unidentified until recently.

Through the use of comprehensive mutation testing, collaborative international efforts, and integration of data from adult trials, critical information is now known regarding even rare genetic lesions that alter outcomes. This has primarily led to a growing list of HR genetic features. Specific KMT2A fusions, DEK-NUP214 and WT1 mutations, ETV6 rearrangements, and CBFA2T3-GLIS2, MECOM, MLLT10, and NUP98 fusions are now included in various cooperative group risk algorithms that recommend SCT in first CR. The potential for benefit of SCT transplant in first CR for these patients remains to be seen. Additionally, challenges surrounding attainment of an MRDnegative $\mathrm{CR}$ using traditional chemotherapy may limit the utility of this approach and continue to highlight the need for additional treatment options for such patients.

The treatment of AML is quickly changing in adults, yet the advances in pediatrics are slower to evolve due to a lack of drugs developed specifically for the pediatric population and the challenges of evaluating novel agents for a relatively rare disease. Standard therapies in adult AML, such as GO and FLT3 inhibitors, have only recently been incorporated into pediatric trials, and the optimal way in which to incorporate them into therapy is still under investigation. In addition, newer agents such as HMAs and DNMT inhibitors have been developed primarily for adults who cannot tolerate intensive cytotoxic therapy, and therefore, acceptable outcomes in this population differ greatly from the desired results in children. However, the use of these agents may prove beneficial when incorporated into relapse regimens in children with pediatric AML.

The continual expansion of recurrent genetic lesions in AML and their effects on outcomes, along with the growing list of therapeutic options, may ultimately provide an opportunity to individualize regimens in pediatric AML. The addition of GO and FLT3 inhibitors to standard chemotherapy regimens is now becoming a standard of care, but more studies are needed on other new agents to determine their utility in children. Through ongoing collaboration and innovation, treatment strategies will become more tailored to the underlying genetics of the disease with resultant improvements in outcome.

\section{Compliance with Ethical Standards}

Conflict of Interest The authors declare that they have no conflict of interest.

Human and Animal Rights This article does not contain any studies with human or animal subjects performed by any of the authors.

Open Access This article is licensed under a Creative Commons Attribution 4.0 International License, which permits use, sharing, adaptation, distribution and reproduction in any medium or format, as long as you give appropriate credit to the original author(s) and the source, provide a link to the Creative Commons licence, and indicate if changes were made. The images or other third party material in this article are included in the article's Creative Commons licence, unless indicated otherwise in a credit line to the material. If material is not included in the article's Creative Commons licence and your intended use is not permitted by statutory regulation or exceeds the permitted use, you will need to obtain permission directly from the copyright holder. To view a copy of this licence, visit http://creativecommons.org/licenses/by/4.0/.

\section{References}

Papers of particular interest, published recently, have been highlighted as:

- Of importance

- Of major importance

1. Aplenc R, Meshinchi S, Sung L, Alonzo T, Choi J, Fisher B, et al. Bortezomib with standard chemotherapy for children with acute myeloid leukemia does not improve treatment outcomes: a report from the Children's Oncology Group. Haematologica. 2020;105: 1879-86. https://doi.org/10.3324/haematol.2019.220962. 
2. Rasche M, Zimmermann M, Borschel L, Bourquin JP, Dworzak $\mathrm{M}, \mathrm{Klingebiel} \mathrm{T,} \mathrm{et} \mathrm{al.} \mathrm{Successes} \mathrm{and} \mathrm{challenges} \mathrm{in} \mathrm{the} \mathrm{treatment}$ of pediatric acute myeloid leukemia: a retrospective analysis of the AML-BFM trials from 1987 to 2012. Leukemia. 2018;32(10): 2167-77. https://doi.org/10.1038/s41375-018-0071-7.

3. Jaffe ES, World Health Organization. Pathology and genetics of tumours of haematopoietic and lymphoid tissues. World Health Organization classification of tumours. Lyon Oxford: IARC Press; Oxford University Press (distributor); 2001.

4. Ho PA, Alonzo TA, Gerbing RB, Pollard J, Stirewalt DL, Hurwitz $\mathrm{C}$, et al. Prevalence and prognostic implications of CEBPA mutations in pediatric acute myeloid leukemia (AML): a report from the Children's Oncology Group. Blood. 2009;113(26):6558-66. https://doi.org/10.1182/blood-2008-10-184747.

5. Brown P, McIntyre E, Rau R, Meshinchi S, Lacayo N, Dahl G, et al. The incidence and clinical significance of nucleophosmin mutations in childhood AML. Blood. 2007;110(3):979-85. https://doi.org/10.1182/blood-2007-02-076604.

6. Hollink IH, Zwaan CM, Zimmermann M, Arentsen-Peters TC, Pieters R, Cloos J, et al. Favorable prognostic impact of NPM1 gene mutations in childhood acute myeloid leukemia, with emphasis on cytogenetically normal AML. Leukemia. 2009;23(2): 262-70. https://doi.org/10.1038/leu.2008.313.

7. Hasle H, Arico M, Basso G, Biondi A, Cantu Rajnoldi A, Creutzig $\mathrm{U}$, et al. Myelodysplastic syndrome, juvenile myelomonocytic leukemia, and acute myeloid leukemia associated with complete or partial monosomy 7. European Working Group on MDS in Childhood (EWOG-MDS). Leukemia. 1999;13(3):376-85. https://doi.org/10.1038/sj.leu.2401342.

8. Woods WG, Barnard DR, Alonzo TA, Buckley JD, Kobrinsky N, Arthur DC, et al. Prospective study of 90 children requiring treatment for juvenile myelomonocytic leukemia or myelodysplastic syndrome: a report from the Children's Cancer Group. J Clin Oncol. 2002;20(2):434-40. https://doi.org/10.1200/JCO.2002. 20.2.434.

9. Balgobind BV, Raimondi SC, Harbott J, Zimmermann M, Alonzo TA, Auvrignon A, et al. Novel prognostic subgroups in childhood 11q23/MLL-rearranged acute myeloid leukemia: results of an international retrospective study. Blood. 2009;114(12):2489-96. https://doi.org/10.1182/blood-2009-04-215152.

10.• Bolouri H, Farrar JE, Triche T Jr, Ries RE, Lim EL, Alonzo TA, et al. The molecular landscape of pediatric acute myeloid leukemia reveals recurrent structural alterations and age-specific mutational interactions. Nat Med. 2018;24(1):103-12. https://doi.org/10. $1038 / \mathrm{nm} .4439$ This study provides a comprehensive description of mutations found in pediatric AML via various testing techniques and compares the mutational landscape to adult AML.

11. Rasche M, von Neuhoff C, Dworzak M, Bourquin JP, Bradtke J, Gohring G, et al. Genotype-outcome correlations in pediatric AML: the impact of a monosomal karyotype in trial AML-BFM 2004. Leukemia. 2017;31(12):2807-14. https://doi.org/10.1038/ leu.2017.121.

12. Papaemmanuil E, Gerstung M, Bullinger L, Gaidzik VI, Paschka $\mathrm{P}$, Roberts ND, et al. Genomic classification and prognosis in acute myeloid leukemia. N Engl J Med. 2016;374(23):2209-21. https://doi.org/10.1056/NEJMoa1516192.

13. Marceau-Renaut A, Duployez N, Ducourneau B, Labopin M, Petit A, Rousseau A, et al. Molecular profiling defines distinct prognostic subgroups in childhood AML: a report from the French ELAM02 Study Group. Hemasphere. 2018;2(1):e31. https://doi. org/10.1097/HS9.0000000000000031 This study details new risk groups in pediatric AML based on newly described common mutations including WT1 and NUP98 fusions.

14. Gamis AS, Alonzo TA, Meshinchi S, Sung L, Gerbing RB, Raimondi SC, et al. Gemtuzumab ozogamicin in children and adolescents with de novo acute myeloid leukemia improves event-free survival by reducing relapse risk: results from the randomized phase III Children's Oncology Group trial AAML0531. J Clin Oncol. 2014;32(27):3021-32. https://doi.org/10.1200/JCO. 2014.55.3628.

15. von Neuhoff C, Reinhardt D, Sander A, Zimmermann M, Bradtke J, Betts DR, et al. Prognostic impact of specific chromosomal aberrations in a large group of pediatric patients with acute myeloid leukemia treated uniformly according to trial AML-BFM 98. J Clin Oncol. 2010;28(16):2682-9. https://doi.org/10.1200/JCO. 2009.25.6321.

16. Harrison CJ, Hills RK, Moorman AV, Grimwade DJ, Hann I, Webb DK, et al. Cytogenetics of childhood acute myeloid leukemia: United Kingdom Medical Research Council Treatment trials AML 10 and 12. J Clin Oncol. 2010;28(16):2674-81. https://doi. org/10.1200/JCO.2009.24.8997.

17. Hara Y, Shiba N, Yamato G, Ohki K, Tabuchi K, Sotomatsu M, et al. Patients aged less than 3 years with acute myeloid leukaemia characterize a molecularly and clinically distinct subgroup. Br J Haematol. 2020;188(4):528-39. https://doi.org/10.1111/bjh. 16203.

18. Tarlock K, Alonzo TA, Gerbing RB, Raimondi SC, Hirsch BA, Sung L, et al. Gemtuzumab ozogamicin reduces relapse risk in FLT3/ITD acute myeloid leukemia: a report from the Children's Oncology Group. Clin Cancer Res. 2016;22(8):1951-7. https:// doi.org/10.1158/1078-0432.CCR-15-1349.

19. Meshinchi S, Alonzo TA, Stirewalt DL, Zwaan M, Zimmerman $\mathrm{M}$, Reinhardt D, et al. Clinical implications of FLT3 mutations in pediatric AML. Blood. 2006;108(12):3654-61. https://doi.org/10. 1182/blood-2006-03-009233.

20. Tarlock K. Distinct co-occurring mutational profiles in acute myeloid leukemia confers prognostic significance in children and young adults with FLT3/ITD mutations. Blood. 2018;132:1 This study demonstrates FLT3-ITD AR 0.1-0.4 confers a similar outcome as $A R>0.4$, providing rationale to use lower AR threshold in future trials.

21. Niktoreh N, Walter C, Zimmermann M, von Neuhoff C, von Neuhoff N, Rasche M, et al. Mutated WT1, FLT3-ITD, and NUP98-NSD1 fusion in various combinations define a poor prognostic group in pediatric acute myeloid leukemia. J Oncol. 2019;2019:1609128-15. https://doi.org/10.1155/2019/1609128.

22. Klein K, Kaspers G, Harrison CJ, Beverloo HB, Reedijk A, Bongers $\mathrm{M}$, et al. Clinical impact of additional cytogenetic aberrations, cKIT and RAS mutations, and treatment elements in pediatric $\mathrm{t}(8 ; 21)$-AML: results from an international retrospective study by the International Berlin-Frankfurt-Munster Study Group. J Clin Oncol. 2015;33(36):4247-58. https://doi.org/10. 1200/JCO.2015.61.1947.

23. Esposito MT. The impact of PI3-kinase/RAS pathway cooperating mutations in the evolution of KMT2A-rearranged leukemia. Hemasphere. 2019;3(3):e195. https://doi.org/10.1097/ HS9.0000000000000195.

24. Ostronoff F, Othus M, Gerbing RB, Loken MR, Raimondi SC, Hirsch BA, et al. NUP98/NSD1 and FLT3/ITD coexpression is more prevalent in younger AML patients and leads to induction failure: a COG and SWOG report. Blood. 2014;124(15):2400-7. https://doi.org/10.1182/blood-2014-04-570929.

25. Tarlock K, Alonzo TA, Wang YC, Gerbing RB, Ries R, Loken $\mathrm{MR}$, et al. Functional properties of KIT mutations are associated with differential clinical outcomes and response to targeted therapeutics in CBF acute myeloid leukemia. Clin Cancer Res. 2019;25(16):5038-48. https://doi.org/10.1158/1078-0432.CCR18-1897.

26. Duployez N, Marceau-Renaut A, Boissel N, Petit A, Bucci M, Geffroy $S$, et al. Comprehensive mutational profiling of core 
binding factor acute myeloid leukemia. Blood. 2016;127(20): 2451-9. https://doi.org/10.1182/blood-2015-12-688705.

27.• Meyer C, Burmeister T, Groger D, Tsaur G, Fechina L, Renneville A, et al. The MLL recombinome of acute leukemias in 2017. Leukemia. 2018;32(2):273-84. https://doi.org/10.1038/leu.2017. 213 This study demonstrates that the prognostic significance of KMT2A rearrangements is dependent on fusion gene partner.

28. Guest EM, Hirsch BA, Kolb EA, Alonzo TA, Gerbing R, Aplenc $\mathrm{R}$, et al. Prognostic significance of 11q23/MLL fusion partners in children with acute myeloid leukemia (AML) - results from the Children's Oncology Group (COG) Trial AAML0531. Blood. 2016;128(22):1211. https://doi.org/10.1182/blood.V128.22. 1211.1211.

29. Borel C, Dastugue N, Cances-Lauwers V, Mozziconacci MJ, Prebet T, Vey N, et al. PICALM-MLLT10 acute myeloid leukemia: a French cohort of 18 patients. Leuk Res. 2012;36(11):13659. https://doi.org/10.1016/j.leukres.2012.07.008.

30. Shiba N, Yoshida K, Hara Y, Yamato G, Shiraishi Y, Matsuo H, et al. Transcriptome analysis offers a comprehensive illustration of the genetic background of pediatric acute myeloid leukemia. Blood Adv. 2019;3(20):3157-69. https://doi.org/10.1182/ bloodadvances.2019000404 This study demonstrates the use of RT-PCR and RNAseq as valuable tools to identify novel fusion genes in pediatric AML.

31. Sandahl JD, Coenen EA, Forestier E, Harbott J, Johansson B, Kerndrup G, et al. t(6;9)(p22;q34)/DEK-NUP214-rearranged pediatric myeloid leukemia: an international study of 62 patients. Haematologica. 2014;99(5):865-72. https://doi.org/10.3324/ haematol.2013.098517.

32. Tarlock K, Alonzo TA, Moraleda PP, Gerbing RB, Raimondi SC, Hirsch BA, et al. Acute myeloid leukaemia (AML) with $\mathrm{t}(6 ; 9)(\mathrm{p} 23 ; \mathrm{q} 34)$ is associated with poor outcome in childhood AML regardless of FLT3-ITD status: a report from the Children's Oncology Group. Br J Haematol. 2014;166(2):254-9. https://doi.org/10.1111/bjh.12852.

33. Qin H, Malek S, Cowell JK, Ren M. Transformation of human CD34+ hematopoietic progenitor cells with DEK-NUP214 induces AML in an immunocompromised mouse model. Oncogene. 2016;35(43):5686-91. https://doi.org/10.1038/onc. 2016.118.

34. Xie W, Hu S, Xu J, Chen Z, Medeiros LJ, Tang G. Acute myeloid leukemia with $\mathrm{t}(8 ; 16)(\mathrm{p} 11.2 ; \mathrm{p} 13.3) / \mathrm{KAT} 6 \mathrm{~A}-\mathrm{CREBBP}$ in adults. Ann Hematol. 2019;98(5):1149-57. https://doi.org/10.1007/ s00277-019-03637-7.

35. Coenen EA, Zwaan CM, Reinhardt D, Harrison CJ, Haas OA, de Haas V, et al. Pediatric acute myeloid leukemia with $\mathrm{t}(8 ; 16)(\mathrm{p} 11 ; \mathrm{p} 13)$, a distinct clinical and biological entity: a collaborative study by the International-Berlin-Frankfurt-Munster AML-study group. Blood. 2013;122(15):2704-13. https://doi. org/10.1182/blood-2013-02-485524.

36. Hollink IH, van den Heuvel-Eibrink MM, Zimmermann M, Balgobind BV, Arentsen-Peters ST, Alders M, et al. Clinical relevance of Wilms tumor 1 gene mutations in childhood acute myeloid leukemia. Blood. 2009;113(23):5951-60. https://doi.org/10. 1182/blood-2008-09-177949.

37. Espersen ADL, Noren-Nystrom U, Abrahamsson J, Ha SY, Pronk CJ, Jahnukainen K, et al. Acute myeloid leukemia (AML) with $\mathrm{t}(7 ; 12)(\mathrm{q} 36 ; \mathrm{p} 13)$ is associated with infancy and trisomy 19: data from Nordic Society for Pediatric Hematology and Oncology (NOPHO-AML) and review of the literature. Genes Chromosom Cancer. 2018;57(7):359-65. https://doi.org/10.1002/gcc.22538.

38. von Bergh AR, van Drunen E, van Wering ER, van Zutven LJ, Hainmann I, Lonnerholm G, et al. High incidence of $\mathrm{t}(7 ; 12)(\mathrm{q} 36 ; \mathrm{p} 13)$ in infant AML but not in infant ALL, with a dismal outcome and ectopic expression of HLXB9. Genes
Chromosom Cancer. 2006;45(8):731-9. https://doi.org/10.1002/ gcc.20335.

39. Masetti R, Pigazzi M, Togni M, Astolfi A, Indio V, Manara E, et al. CBFA2T3-GLIS2 fusion transcript is a novel common feature in pediatric, cytogenetically normal AML, not restricted to FAB M7 subtype. Blood. 2013;121(17):3469-72. https://doi.org/ 10.1182/blood-2012-11-469825.

40. Smith JL, Ries RE, Hylkema T, Alonzo TA, Gerbing RB, Santaguida MT, et al. Comprehensive transcriptome profiling of cryptic CBFA2T3-GLIS2 fusion-positive AML defines novel therapeutic options: a COG and TARGET pediatric AML study. Clin Cancer Res. 2020;26(3):726-37. https://doi.org/10.1158/ 1078-0432.CCR-19-1800.

41. Hara Y, Shiba N, Ohki K, Tabuchi K, Yamato G, Park MJ, et al. Prognostic impact of specific molecular profiles in pediatric acute megakaryoblastic leukemia in non-Down syndrome. Genes Chromosom Cancer. 2017;56(5):394-404. https://doi.org/10. $1002 /$ gcc. 22444 .

42. Hollink IH, van den Heuvel-Eibrink MM, Arentsen-Peters ST, Pratcorona M, Abbas S, Kuipers JE, et al. NUP98/NSD1 characterizes a novel poor prognostic group in acute myeloid leukemia with a distinct HOX gene expression pattern. Blood. 2011;118(13):3645-56. https://doi.org/10.1182/blood-2011-04346643.

43. Noort S, Wander P, Alonzo TA, Smith J, Ries RE, Gerbing RB, et al. The clinical and biological characteristics of NUP98KDM5A in pediatric acute myeloid leukemia. Haematologica. 2020:haematol.2019.236745. https://doi.org/10.3324/haematol. 2019.236745.

44. Slater RM, von Drunen E, Kroes WG, Weghuis DO, van den Berg E, Smit EM, et al. T(7;12)(q36;p13) and t(7;12)(q32;p13)-translocations involving ETV6 in children 18 months of age or younger with myeloid disorders. Leukemia. 2001;15(6):915-20. https:// doi.org/10.1038/sj.leu.2402121.

45. Naito K, Takeshita A, Shigeno K, Nakamura S, Fujisawa S, Shinjo K, et al. Calicheamicin-conjugated humanized anti-CD33 monoclonal antibody (gemtuzumab ozogamicin, CMA-676) shows cytocidal effect on CD33-positive leukemia cell lines, but is inactive on P-glycoprotein-expressing sublines. Leukemia. 2000;14(8):1436-43. https://doi.org/10.1038/sj.leu.2401851.

46. Walter RB, Appelbaum FR, Estey EH, Bernstein ID. Acute myeloid leukemia stem cells and CD33-targeted immunotherapy. Blood. 2012;119(26):6198-208. https://doi.org/10.1182/blood2011-11-325050.

47. Hills RK, Castaigne S, Appelbaum FR, Delaunay J, Petersdorf S, Othus M, et al. Addition of gemtuzumab ozogamicin to induction chemotherapy in adult patients with acute myeloid leukaemia: a meta-analysis of individual patient data from randomised controlled trials. Lancet Oncol. 2014;15(9):986-96. https://doi.org/ 10.1016/S1470-2045(14)70281-5.

48. Loke J, Khan JN, Wilson JS, Craddock C, Wheatley K. Mylotarg has potent anti-leukaemic effect: a systematic review and metaanalysis of anti-CD33 antibody treatment in acute myeloid leukaemia. Ann Hematol. 2015;94(3):361-73. https://doi.org/10.1007/ s00277-014-2218-6.

49. Castaigne S, Pautas C, Terre C, Raffoux E, Bordessoule D, Bastie $\mathrm{JN}$, et al. Effect of gemtuzumab ozogamicin on survival of adult patients with de-novo acute myeloid leukaemia (ALFA-0701): a randomised, open-label, phase 3 study. Lancet. 2012;379(9825): 1508-16. https://doi.org/10.1016/S0140-6736(12)60485-1.

50. Burnett A, Cavenagh J, Russell N, Hills R, Kell J, Jones G, et al. Defining the dose of gemtuzumab ozogamicin in combination with induction chemotherapy in acute myeloid leukemia: a comparison of $3 \mathrm{mg} / \mathrm{m} 2$ with $6 \mathrm{mg} / \mathrm{m} 2$ in the NCRI AML17 Trial. Haematologica. 2016;101(6):724-31. https://doi.org/10.3324/ haematol.2016.141937. 
51. Niktoreh N, Lerius B, Zimmermann M, Gruhn B, Escherich G, Bourquin JP, et al. Gemtuzumab ozogamicin in children with relapsed or refractory acute myeloid leukemia: a report by Berlin-Frankfurt-Munster study group. Haematologica. 2019;104(1):120-7. https://doi.org/10.3324/haematol.2018. 191841.

52. Hasle H, Abrahamsson J, Forestier E, Ha SY, Heldrup J, Jahnukainen K, et al. Gemtuzumab ozogamicin as postconsolidation therapy does not prevent relapse in children with AML: results from NOPHO-AML 2004. Blood. 2012;120(5):978-84. https://doi.org/10.1182/blood-2012-03416701.

53. Rafiee R, Chauhan L, Alonzo TA, Wang YC, Elmasry A, Loken MR, et al. ABCB1 SNP predicts outcome in patients with acute myeloid leukemia treated with gemtuzumab ozogamicin: a report from Children's Oncology Group AAML0531 Trial. Blood Cancer J. 2019;9(6):51. https://doi.org/10.1038/s41408-0190211-y.

54. Lamba JK, Chauhan L, Shin M, Loken MR, Pollard JA, Wang YC, et al. CD33 splicing polymorphism determines gemtuzumab ozogamicin response in de novo acute myeloid leukemia: report from randomized phase III Children's Oncology Group Trial AAML0531. J Clin Oncol. 2017;35(23):2674-82. https://doi. org/10.1200/JCO.2016.71.2513.

55. Pollard JA, Loken M, Gerbing RB, Raimondi SC, Hirsch BA, Aplenc R, et al. CD33 expression and its association with gemtuzumab ozogamicin response: results from the randomized phase III Children's Oncology Group Trial AAML0531. J Clin Oncol. 2016;34(7):747-55. https://doi.org/10.1200/JCO.2015.62. 6846.

56. Ehninger A, Kramer M, Rollig C, Thiede C, Bornhauser M, von Bonin $\mathrm{M}$, et al. Distribution and levels of cell surface expression of CD33 and CD123 in acute myeloid leukemia. Blood Cancer J. 2014;4:e218. https://doi.org/10.1038/bcj. 2014.39.

57. Kovtun Y, Jones GE, Adams S, Harvey L, Audette CA, Wilhelm A, et al. A CD123-targeting antibody-drug conjugate, IMGN632, designed to eradicate AML while sparing normal bone marrow cells. Blood Adv. 2018;2(8):848-58. https://doi.org/10.1182/ bloodadvances.2018017517.

58. Campagne O, Delmas A, Fouliard S, Chenel M, Chichili GR, Li $\mathrm{H}$, et al. Integrated pharmacokinetic/pharmacodynamic model of a bispecific CD3xCD123 DART molecule in nonhuman primates: evaluation of activity and impact of immunogenicity. Clin Cancer Res. 2018;24(11):2631-41. https://doi.org/10.1158/1078-0432. CCR-17-2265.

59. Daver N, Garcia-Manero G, Basu S, Boddu PC, Alfayez M, Cortes JE, et al. Efficacy, safety, and biomarkers of response to azacitidine and nivolumab in relapsed/refractory acute myeloid leukemia: a nonrandomized, open-label, phase II study. Cancer Discov. 2019;9(3):370-83. https://doi.org/10.1158/2159-8290. CD-18-0774.

60. Albring JC, Inselmann S, Sauer T, Schliemann C, Altvater B, Kailayangiri S, et al. PD-1 checkpoint blockade in patients with relapsed AML after allogeneic stem cell transplantation. Bone Marrow Transplant. 2017;52(2):317-20. https://doi.org/10.1038/ bmt.2016.274.

61. Broglie L, Gershan J, Burke MJ. Checkpoint inhibition of PD-L1 and CTLA-4 in a child with refractory acute leukemia. Int J Hematol Oncol. 2019;8(1):IJH10. https://doi.org/10.2217/ijh2018-0009.

62. Loff S, Dietrich J, Meyer JE, Riewaldt J, Spehr J, von Bonin M, et al. Rapidly switchable universal CAR-T cells for treatment of CD123-positive leukemia. Mol Ther Oncolytics. 2020;17:40820. https://doi.org/10.1016/j.omto.2020.04.009.
63. Cruijsen M, Lubbert M, Wijermans P, Huls G. Clinical results of hypomethylating agents in AML treatment. J Clin Med. 2014;4(1):1-17. https://doi.org/10.3390/jcm4010001.

64. Zeidan AM, Wang R, Wang X, Shallis RM, Podoltsev NA, Bewersdorf JP, et al. Clinical outcomes of older patients with AML receiving hypomethylating agents: a large populationbased study in the United States. Blood Adv. 2020;4(10):2192201. https://doi.org/10.1182/bloodadvances.2020001779.

65. Blum W, Sanford BL, Klisovic R, DeAngelo DJ, Uy G, Powell $\mathrm{BL}$, et al. Maintenance therapy with decitabine in younger adults with acute myeloid leukemia in first remission: a phase 2 Cancer and Leukemia Group B Study (CALGB 10503). Leukemia. 2017;31(1):34-9. https://doi.org/10.1038/leu.2016.252.

66. Keino D, Mori T, Morimoto M, Kondo K, Mori T, Kinoshita A. Salvage therapy with azacitidine for pediatric acute myeloid leukemia with $\mathrm{t}(16 ; 21)(\mathrm{p} 11 ; \mathrm{q} 22) / \mathrm{FUS}-\mathrm{ERG}$ and early relapse after allogeneic blood stem cell transplantation: a case report. Clin Case Rep. 2019;7(11):2149-52. https://doi.org/10.1002/ccr3.2461.

67. Raedler J, Heyde S, Kolokythas M, Eichinger A, Binder V, Schmid I, et al. Venetoclax and decitabine for relapsed paediatric myelodysplastic syndrome-related acute myeloid leukaemia with complex aberrant karyotype after second stem cell transplantation. Br J Haematol. 2020;189(6):e251-e4. https://doi.org/10.1111/bjh. 16682.

68. Sun W, Triche T Jr, Malvar J, Gaynon P, Sposto R, Yang X, et al. A phase 1 study of azacitidine combined with chemotherapy in childhood leukemia: a report from the TACL consortium. Blood. 2018;131(10):1145-8. https://doi.org/10.1182/blood-2017-09803809.

69. Quintas-Cardama A, Santos FP, Garcia-Manero G. Histone deacetylase inhibitors for the treatment of myelodysplastic syndrome and acute myeloid leukemia. Leukemia. 2011;25(2):22635. https://doi.org/10.1038/leu.2010.276.

70. Maiso P, Colado E, Ocio EM, Garayoa M, Martin J, Atadja P, et al. The synergy of panobinostat plus doxorubicin in acute myeloid leukemia suggests a role for HDAC inhibitors in the control of DNA repair. Leukemia. 2009;23(12):2265-74. https://doi.org/ 10.1038/leu.2009.182.

71. Gopalakrishnapillai A, Kolb EA, McCahan SM, Barwe SP. Epigenetic drug combination induces remission in mouse xenograft models of pediatric acute myeloid leukemia. Leuk Res. 2017;58:91-7. https://doi.org/10.1016/j.leukres.2017.05.004.

72. Young CS, Clarke KM, Kettyle LM, Thompson A, Mills KI. Decitabine-vorinostat combination treatment in acute myeloid leukemia activates pathways with potential for novel triple therapy. Oncotarget. 2017;8(31):51429-46. https://doi.org/10.18632/ oncotarget. 18009 .

73. DeAngelo DJ, Walker AR, Schlenk RF, Sierra J, Medeiros BC, Ocio EM, et al. Safety and efficacy of oral panobinostat plus chemotherapy in patients aged 65 years or younger with highrisk acute myeloid leukemia. Leuk Res. 2019;85:106197. https:// doi.org/10.1016/j.leukres.2019.106197.

74. Craddock CF, Houlton AE, Quek LS, Ferguson P, Gbandi E, Roberts $\mathrm{C}$, et al. Outcome of azacitidine therapy in acute myeloid leukemia is not improved by concurrent vorinostat therapy but is predicted by a diagnostic molecular signature. Clin Cancer Res. 2017;23(21):6430 40. https://doi.org/10.1158/1078-0432.CCR-17-1423.

75. Chew S, Mackey MC, Jabbour E. Gilteritinib in the treatment of relapsed and refractory acute myeloid leukemia with a FLT3 mutation. Ther Adv Hematol. 2020;11:2040620720930614. https:// doi.org/10.1177/2040620720930614.

76. Ke YY, Singh VK, Coumar MS, Hsu YC, Wang WC, Song JS, et al. Homology modeling of DFG-in FMS-like tyrosine kinase 3 (FLT3) and structure-based virtual screening for inhibitor identification. Sci Rep. 2015;5:11702. https://doi.org/10.1038/ srep11702. 
77. Ravandi F, Arana Yi C, Cortes JE, Levis M, Faderl S, GarciaManero G, et al. Final report of phase II study of sorafenib, cytarabine and idarubicin for initial therapy in younger patients with acute myeloid leukemia. Leukemia. 2014;28(7):1543-5. https://doi.org/10.1038/leu.2014.54.

78. Rollig C, Serve H, Huttmann A, Noppeney R, Muller-Tidow C, Krug U, et al. Addition of sorafenib versus placebo to standard therapy in patients aged 60 years or younger with newly diagnosed acute myeloid leukaemia (SORAML): a multicentre, phase 2, randomised controlled trial. Lancet Oncol. 2015;16(16):1691-9. https://doi.org/10.1016/S1470-2045(15)00362-9.

79. Inaba H, Rubnitz JE, Coustan-Smith E, Li L, Furmanski BD, Mascara GP, et al. Phase I pharmacokinetic and pharmacodynamic study of the multikinase inhibitor sorafenib in combination with clofarabine and cytarabine in pediatric relapsed/refractory leukemia. J Clin Oncol. 2011;29(24):3293-300. https://doi.org/10. 1200/JCO.2011.34.7427.

80. Pollard JA. Sorafenib in combination with standard chemotherapy for children with high allelic ratio FLT3/ITD+ AML improves event-free survival and reduces relapse risk: a report from the Children's Oncology Group Protocol AAML1031. Orlando, FL: Blood: American Society of Hematology Annual Meeting; 2019.

81. Fischer T, Stone RM, Deangelo DJ, Galinsky I, Estey E, Lanza C, et al. Phase IIB trial of oral midostaurin (PKC412), the FMS-like tyrosine kinase 3 receptor (FLT3) and multi-targeted kinase inhibitor, in patients with acute myeloid leukemia and high-risk myelodysplastic syndrome with either wild-type or mutated FLT3. J Clin Oncol. 2010;28(28):4339-45. https://doi.org/10. 1200/JCO.2010.28.9678.

82. Stone RM, Mandrekar SJ, Sanford BL, Laumann K, Geyer S, Bloomfield CD, et al. Midostaurin plus chemotherapy for acute myeloid leukemia with a FLT3 mutation. N Engl J Med. 2017;377(5):454-64. https://doi.org/10.1056/NEJMoa1614359.

83. Schumich A, Prchal-Murphy M, Maurer-Granofszky M, HoelblKovacic A, Muhlegger N, Potschger U, et al. Phospho-profiling linking biology and clinics in pediatric acute myeloid leukemia. Hemasphere. 2020;4(1):e312. https://doi.org/10.1097/HS9. 0000000000000312.

84. Park IK, Mundy-Bosse B, Whitman SP, Zhang X, Warner SL, Bearss DJ, et al. Receptor tyrosine kinase Axl is required for resistance of leukemic cells to FLT3-targeted therapy in acute myeloid leukemia. Leukemia. 2015;29(12):2382-9. https://doi. org/10.1038/leu.2015.147.

85. Perl AE, Altman JK, Cortes J, Smith C, Litzow M, Baer MR, et al. Selective inhibition of FLT3 by gilteritinib in relapsed or refractory acute myeloid leukaemia: a multicentre, first-in-human, openlabel, phase 1-2 study. Lancet Oncol. 2017;18(8):1061-75. https:// doi.org/10.1016/S1470-2045(17)30416-3.

86. Perl AE, Martinelli G, Cortes JE, Neubauer A, Berman E, Paolini $\mathrm{S}$, et al. Gilteritinib or chemotherapy for relapsed or refractory FLT3-mutated AML. N Engl J Med. 2019;381(18):1728-40. https://doi.org/10.1056/NEJMoa1902688.

87. Ueno Y, Mori M, Kamiyama Y, Saito R, Kaneko N, Isshiki E, et al. Evaluation of gilteritinib in combination with chemotherapy in preclinical models of FLT3-ITD(+) acute myeloid leukemia. Oncotarget. 2019;10(26):2530-45. https://doi.org/10.18632/ oncotarget.26811.

88. McMahon CM, Perl AE. Gilteritinib for the treatment of relapsed and/or refractory FLT3-mutated acute myeloid leukemia. Expert Rev Clin Pharmacol. 2019;12(9):841-9. https://doi.org/10.1080/ 17512433.2019.1657009.

89. Konopleva M, Zhao S, Hu W, Jiang S, Snell V, Weidner D, et al. The anti-apoptotic genes Bcl-X(L) and Bcl-2 are over-expressed and contribute to chemoresistance of non-proliferating leukaemic CD34+ cells. Br J Haematol. 2002;118(2):521-34. https://doi.org/ 10.1046/j.1365-2141.2002.03637.x.
90. Bewersdorf JP, Giri S, Wang R, Williams RT, Tallman MS, Zeidan AM, et al. Venetoclax as monotherapy and in combination with hypomethylating agents or low dose cytarabine in relapsed and treatment refractory acute myeloid leukemia: a systematic review and meta-analysis. Haematologica. 2020;105:2659-63. https://doi.org/10.3324/haematol.2019.242826.

91. Karol SE, Alexander TB, Budhraja A, Pounds SB, Canavera K, Wang $\mathrm{L}$, et al. Venetoclax in combination with cytarabine with or without idarubicin in children with relapsed or refractory acute myeloid leukaemia: a phase 1, dose-escalation study. Lancet Oncol. 2020;21(4):55160. https://doi.org/10.1016/S1470-2045(20)30060-7.

92. Ma J, Zhao S, Qiao X, Knight T, Edwards H, Polin L, et al. Inhibition of Bcl-2 synergistically enhances the antileukemic activity of midostaurin and gilteritinib in preclinical models of FLT3-mutated acute myeloid leukemia. Clin Cancer Res. 2019;25(22):6815-26. https://doi.org/10.1158/1078-0432.CCR-19-0832.

93. Mayer LD, Harasym TO, Tardi PG, Harasym NL, Shew CR, Johnstone SA, et al. Ratiometric dosing of anticancer drug combinations: controlling drug ratios after systemic administration regulates therapeutic activity in tumor-bearing mice. Mol Cancer Ther. 2006;5(7):1854-63. https://doi.org/10.1158/1535-7163. MCT-06-0118.

94. Nikanjam M, Capparelli EV, Lancet JE, Louie A, Schiller G. Persistent cytarabine and daunorubicin exposure after administration of novel liposomal formulation CPX-351: population pharmacokinetic assessment. Cancer Chemother Pharmacol. 2018;81(1):171-8. https://doi.org/10.1007/s00280-017-3484-5.

95. Cortes JE, Goldberg SL, Feldman EJ, Rizzeri DA, Hogge DE, Larson M, et al. Phase II, multicenter, randomized trial of CPX351 (cytarabine:daunorubicin) liposome injection versus intensive salvage therapy in adults with first relapse AML. Cancer. 2015;121(2):234-42. https://doi.org/10.1002/cncr.28974.

96. Lancet JE, Uy GL, Cortes JE, Newell LF, Lin TL, Ritchie EK, et al. CPX-351 (cytarabine and daunorubicin) liposome for injection versus conventional cytarabine plus daunorubicin in older patients with newly diagnosed secondary acute myeloid leukemia. J Clin Oncol. 2018;36(26):2684-92. https://doi.org/10.1200/JCO.2017.77.6112.

97. Cooper TM, Absalon MJ, Alonzo TA, Gerbing RB, Leger KJ, Hirsch BA, et al. Phase I/II study of CPX-351 followed by fludarabine, cytarabine, and granulocyte-colony stimulating factor for children with relapsed acute myeloid leukemia: a report from the Children's Oncology Group. J Clin Oncol. 2020;38(19):2170 2177. https://doi.org/10.1200/JCO.19.03306 This study provides rationale for the use of CPX-351 in children as it is safe and effective in relapsed pediatric AML.

98. Fry M, Pudney M. Site of action of the antimalarial hydroxynaphthoquinone, 2-[trans-4-(4'-chlorophenyl) cyclohexyl]-3hydroxy-1,4-naphthoquinone (566C80). Biochem Pharmacol. 1992;43(7):1545-53. https://doi.org/10.1016/0006-2952(92)90213-3.

99. Xiang M, Kim H, Ho VT, Walker SR, Bar-Natan M, Anahtar M, et al. Gene expression-based discovery of atovaquone as a STAT3 inhibitor and anticancer agent. Blood. 2016;128(14):1845-53. https://doi.org/10.1182/blood-2015-07-660506.

100. Stevens AM, Xiang M, Heppler LN, Tosic I, Jiang K, Munoz JO, et al. Atovaquone is active against AML by upregulating the integrated stress pathway and suppressing oxidative phosphorylation. Blood Adv. 2019;3(24):4215-27. https://doi.org/10.1182/ bloodadvances.2019000499.

101. Gronningsaeter IS, Reikvam H, Aasebo E, Bartaula-Brevik S, Tvedt $\mathrm{TH}$, Bruserud $\mathrm{O}$, et al. Targeting cellular metabolism in acute myeloid leukemia and the role of patient heterogeneity. Cells. 2020;9(5). https://doi.org/10.3390/cells9051155.

Publisher's Note Springer Nature remains neutral with regard to jurisdictional claims in published maps and institutional affiliations. 